\title{
Vocational and Educational Problems of Epileptic Patients
}

\author{
E. RODIN, P. RENNICK, R. DENNERLL AND Y. LIN \\ Epilepsy Center of Michigan and Lafayche Clinic, Detroit, and Computer Center, University of Michigan, \\ Ann Arbor, Mich. (U.S.A.)
}

During the past few years we have studied the factors which relate to success or failure of epileptic patients on the employment market; preliminary reports have dealt with methodology and some results have already been published (Dennerll et al. 1966, 1968; Dennerll 1970). I will recapitulate certain salient features here. One hundred and fourteen male and 63 female epileptic patients, referred from many sources and who had completed their education, comprised the basic sample. All subjects received detailed evaluations covering the neurological status, psychological functions, as well as their occupational history and work attitudes. The assessment of the patients took between 2.5 and 3 days. All the information was coded and over 1000 variables were available for statistical analysis. Initially, two groups were formed: one consisting of 87 currently employed, and the other of 90 currently unemployed patients, and these were compared on all parameters. The main findings were that the employed patients had higher intelligence, less impairment on neuropsychological tests, less neurological and electroencephalographic abnormalities, and their work history was considerably better than that of the unemployed group. Inasmuch as current employment may depend upon situational and general economic factors, we subsequently divided the total group into three subgroups depending upon percent of time employed during their employable years. It was found that less than $30 \%$ of lifetime employment correlated very highly with current unemployment, while $70 \%$ or more lifetime employment was common in the currently employed group. The 3 groups were found to differ on such a wide variety of measures that it is not feasible to present the individual findings, and summary statements will have to be made.

The neurological history did not differentiate between the groups: particularly the etiology of the seizure disorder, and the seizure frequency, severity and type were not

Presented at the 4th European Symposium on Epilepsy, held 6-8 September, 1971, in Amsterdam (The Netherlands).

This work was supported in part by a grant from the Vocational Rehabilitation Administration.

Key words : Education - Epilepsy - Intelligence - Occupation - Seizure frequency 
relevant. The only items which did show statistically significant differences reflected social attitudes: the number of friends the patient had in adolescence and his present level of socialization. These were better in the group that tended to remain employed The neurological examination yielded more information; abnormal findings in the least employed group relate mostly to impairment of higher cortical functions and cerebellar damage (Table 1). From the EEG, the only relevant finding was slowing of the background rhythm rather than amount of seizure discharges. Although the least employed group tended to have more seizure discharges, both focal and non-focal, the finding did not reach statistical significance.

TABLE 1

\begin{tabular}{lr}
\hline & $F$ \\
\hline Estimated IQ & 11.6 \\
Imitating motions performed in mirror fashion & 11.2 \\
Dull facial expression & 10.7 \\
Tandem gait impaired & 8.0 \\
Rapid alternate motion rate - left hand & \\
decreased & 7.6 \\
Muscular coordination in general decreased & 7.4 \\
General motor activity decreased & 6.5 \\
Graphesthesia - left hand decreased & 6.3 \\
Proverb interpretation concrete & 6.0 \\
Poor observation of imitating motions & 5.9 \\
Homolateral face-hand test impaired & 5.9 \\
Finger wiggling on left decreased & 5.8 \\
Hopping - left leg decreased & 5.6 \\
Rapid alternate motions - right hand decreased & 5.6 \\
Similarities and differences interpreted in & \\
concrete fashion & 5.6 \\
Standing on left leg impaired & 5.5 \\
Rapid alternate motions - left foot decreased & 5.5 \\
Toe wiggling on left decreased & 5.3 \\
Hoffmann's sign present on the left & 5.1 \\
Hoffmann's sign present on the right & 4.9 \\
Finger-nose test on the left impaired & 4.9 \\
Hopping - right leg impaired & 4.7 \\
Synkinesis & 4.4 \\
Decreased amount of speech & 4.3 \\
Standing on right leg impaired & 4.3 \\
Heel to knee test on left impaired & 4.2 \\
Serial 7 subtractions impaired & 3.9 \\
Swaying on Romberg test & 3.5 \\
Knee jerk on left decreased & 3.5 \\
Finger-nose test on right impaired & 3.4 \\
Ocular pursuit movement acadic & 3.3 \\
Knee jerk on right decreased & 3.3 \\
Toe wiggling on right decreased & 3.3 \\
Graphesthesia - right hand decreased & 3.2 \\
Gait impaired & 3.1 \\
Running impaired & 3.1 \\
Nystagmus on lateral gaze & 3.0 \\
\hline &
\end{tabular}


The main findings came from the areas of psychology and job-related attitudes. The group with longest lifetime employment had higher intelligence, less impairment on neuropsychological tests, and obtained better scores on aspects of the California Personality Inventory. They were better informed on ways of seeking jobs, had significantly better self-concepts and higher motivation towards work. It is of course interesting that these are general characteristics of an individual and not directly related to the presence or absence of epilepsy.

Although other studies like those by Juul-Jensen (1961), De Torres (1963), Porter (1968), Ketz (1970) and Walker (1957) had also pointed out that seizure frequency is not important for gaining or maintaining employment, it does seem rather strange and caused us to take a second look at the data. Since there are different social pressures towards employment on the male and on the female, we concentrated now only on the 114 males in the group in order to get as clear a picture as possible (Table 2). Of 26 patients who have not had a seizure during the preceding year, $80 \%$ are employed, while this is the case in only $46 \%$ of the non-remitted patients and the difference is statistically significant (Table 2). When the frequency of seizures is broken down further, as shown in Table 3, this effect is diluted and the differences do not average as statistically significant. This is an example for the statement that total control of

TABLE 2

114 MALES WITH COMPLETED EDUCATION

\begin{tabular}{lcc}
\multicolumn{1}{c}{ Seizure frequency } & Employed & Unemployed \\
\hline Less than once a year & 21 & 5 \\
Once a year or more & 41 & 47 \\
$\quad$ Total & 62 & 52 \\
\hline $\begin{array}{l}\chi^{2}=9.45 \text {. } \\
P<0.01 .\end{array}$ & & \\
\end{tabular}

TABLE 3

114 MALES WITH COMPLETED EDUCATION

\begin{tabular}{lcc}
\hline \multicolumn{1}{c}{ Seizure frequency } & Employed & Unemployed \\
\hline Less than once a year & 21 & 5 \\
About once a year & 3 & 3 \\
2-3 a year & 4 & 9 \\
4-6 a year & 5 & 7 \\
7-12 a year & 4 & 3 \\
Once a month & 5 & 4 \\
2-3 a month & 10 & 5 \\
Once a week & 0 & 3 \\
Several a week & 10 & 12 \\
$\quad$ & 62 & 52 \\
\hline \multicolumn{1}{c}{ Total } & & \\
\hline
\end{tabular}

$t=1.68$, not significant. 
seizures must be our goal rather than mere reduction of seizure frequency (Rodin 1972).

From the combined pool of variables, we selected subsequently 22 which had shown the highest significant differences between the groups, trying to give representation to: general and specific abilities; personality traits; vocational interests and motivation; psychological and neurological findings suggestive of brain damage; EEG variables; presence or absence of seizure remission. Nineteen of these variables were more or less objectively determined from psychological tests, self-inventories, specific neurological signs, etc., while 3 came from interviewing the subject under such conditions that knowledge by the interviewer of the subject's employment status was highly probable. The 22 variables are listed in Table 4 . The 3 interview variables are items 16 , 17 and 22. The remission score is recorded as an interview variable, though the likelihood for bias or misjudgment on the part of the neurologist is of course less than for a variable like "social isolation at present".

TABLE 4

LIST OF VARIABLES SELECTED FOR DISCRIMINANT FUNCTION ANALYSIS

\begin{tabular}{l} 
1. WAIS Verbal IQ \\
2. WAIS Performance IQ \\
3. California Personality Inventory : Dominance \\
4. California Personality Inventory: Capacity for Status \\
5. California Personality Inventory : Sociability \\
6. California Personality Inventory : Social Presence \\
7. California Personality Inventory : Self-Acceptance \\
8. Lin Real Self-Concept Scale: Nervous versus Calm \\
9. Halsted Category Test: Total Errors \\
10. Halsted Tactual Performance Test : Time with Both Hands \\
11. Bender-Gestalt : Overall Disturbance Rating \\
12. Minnesota Percepto-Diagnostic Test: Score on Card No. 4 \\
13. Jenkins Interest Scale: Literary Productivity \\
14. Work Value Scale: :I feel that I can get a good job when I want it." \\
15. Work Value Scale: "I get nervous when my boss is watching me work." \\
16. Psychologist's Interview: Rating of Employment Motivation \\
17. Neurologist's Interview: Rating of Present Social Isolation \\
18. Neurological Examination: Abnormalities of Tandem Gait \\
19. Neurological Examination: Incoordination of Rapid Alternating Motions \\
20. Neurological Examination: Errors in Imitating Motions \\
21. EEG: Amount of theta activity \\
22. Epileptic Disorder: in remission for 1 year or more \\
\hline
\end{tabular}

In order to find from this group of variables the ones that discriminate best between employed and unemployed patients, a step-wise discriminant function analysis was performed. Two different discriminant functions were obtained : one with only the 19 non-interview variables, and the other with all 22 variables. In each case, the program selected the variables in succession, depending on how much they could contribute to the criterion of employed versus unemployed. The effect of adding each successive variable was looked at and, when the minimal most reproducible set was extracted, the discriminant functions reported herein were obtained. When using correlated 
variables, the first few entered into a step-wise discriminant analysis account for most of the variance. If the program is allowed to continue inserting all variables in the equation, classification accuracy generally goes up very slowly, while the $F$ statistic indicating the probable replicability of the equation derived goes down at an alarming rate. This happens even when all the variables initially introduced in the analysis have individually high discriminating power on the criterion. The result of the analysis is a pair of linear equations providing a constant, plus coefficients for each of the few variables entered. When the scores for each subject on that particular test are entered into the two equations, the two resultant scores may be used to classify him with the highest probability into the proper criterion group. The equation gives the best relative weighting of each of the successively added scores so as to optimize this prediction. It is not appropriate here to give all the full details of the equation and the discriminant scores for each of the subjects, but these can be obtained through the Epilepsy Center of Michigan (Dennerll et al. 1968).

On the discriminant analysis, which included the interview variables, the rating of employment motivation made by our psychologists after an interview with the patient showed the highest discriminating power. Of the 62 employed subjects, only 5 were rated as poorly motivated to work, but only 25 of the 52 unemployed subjects were also rated as poorly motivated to work.

The next variable that appeared was Verbal IQ. In conjunction with Employment Motivation, it did not improve the overall classification accuracy very greatly, correctly classifying 31 of the 114 subjects as opposed to 32 when only the Employment Motivation rating was used. It did, however, distribute the errors more proportionately. Of the 62 employed subjects, 49 were correctly classified and 13 misclassified, while of the 52 unemployed subjects, 34 were correctly classified and 18 misclassified.

The next variable was from the Work Value Scale in which the subject had to express agreement or disagreement with the statement : "I feel that I can get a good job when I want it." This is a type of "selfconfidence" variable and would be expected to identify the discouraged epileptic patient who feels that his disease prevents him from access to good opportunities. The classification accuracy improved somewhat : 46 correct versus 16 incorrect in the employed, and 40 correct versus 12 incorrect in the unemployed group.

The next and final variable was the Neurologist's Rating of the patient's present Social Isolation. With this added to the other three, the overall classification accuracy improved somewhat further: 48 correct versus 14 incorrect in the employed group, and 42 correct versus 10 incorrect in the unemployed group.

At this point, the addition of the remaining variables began to increase the classification error, as well as decrease the overall $F$ for the classification table. The result with these 4 variables was an overall accuracy of 90 correct out of 114 , or $79 \%$. It is noteworthy that apart from Verbal IQ, none of the general or specific ability variables, cerebral dysfunction indicators (neurological or neuropsychological), California Personality Inventory variables, EEG variables, or even the variable of "Remission of Epilepsy" appeared in the final equation. This does not mean that they are unimportant, rather it means that the few variables selected correlated sufficiently with the rest so that the contribution of those remaining was unnecessary in the presence of the key variables.

In the discriminant analysis, excluding interview variables, the following appeared as discriminators:

The highest was Verbal IQ and quite powerful in its own right : 44 correct versus 18 incorrect in the employed subjects; 34 correct versus 18 incorrect in the unemployed subjects.

The second variable selected by the program was the Work Value Scale item: "I feel that I can get a good 
job when I want it." With the addition of this variable, the overall accuracy improved: again 44 correct versus 18 incorrect in the employed patients; but 41 correct versus 11 incorrect in the unemployed patients.

The third and final variable which appeared was from the Lin Real Self-Concept Scale: Nervous versus Calm. In this self-inventory scale based on Semantic Differential Methodology, the subject identifies his own position on a line stretching from "nervous" to "calm". The subjects who rated themselves near the calm end of the scale were more likely to be employed. This variable slightly increased the classification accuracy to: 43 correct versus 19 incorrect in the employed patients, but 44 correct versus only 8 correct in the unemployed patients.

At this point, further variables entered began to have a deleterious effect on the overall classification. The final accuracy, $76 \%$, very closely approximates the accuracy obtained from the first set of equations containing 3 variables, which come from possibly somewhat biased interview material. It is interesting to note that the key elements in the final discriminant equation between employed and unemployed subjects are Verbal IQ, together with 2 self-inventory items related to self-confidence.

The study has shown in essence that, in presence of adequate intelligence and proper motivation, epileptic patients can overcome discrimination and maintain employment. But this is of course only part of the problem. It is important to be employed, but it is at least equally important in what capacity the individual earns a living. In our neurology coding sheets, we have a column dealing with "usual occupation of patient" and, since we wanted to make sure that adequate time had elapsed between the individual's completed schooling and final employment state, we concentrated solely on patients above the age of 21 years. From the Vocational Rehabilitation Administration (VRA) project, 127 patients qualified for inclusion and, in order to check on the validity of the finding, we collected information on an additional group of 69 patients in the same age bracket who had been seen for diagnostic evaluation at the Center during the past 5 years and had not participated in the VRA study (Table 5). There was considerable agreement between these two groups of patients, two-thirds to three-quarters belonging to the lowest socio-economic bracket. Inasmuch as the type of employment depends also on the state of the economy at large, we compared the employment status of our epileptic patients with that of the total labor force in the Detroit Metropolitan area. We also obtained the report from the Research and Statistics Division of the Michigan Employment Security Commission on minor-

TABLE 5

OCCUPATIONAL LEVEL OF MALES AND FEMALES ABOVE AGE 21

\begin{tabular}{lcc}
\hline & $\begin{array}{c}\text { VRA } \\
(N=127) \\
(\%)\end{array}$ & $\begin{array}{c}\text { Non-VRA } \\
(N=69) \\
(\%)\end{array}$ \\
\hline $\begin{array}{l}\text { Habitually unemployed } \\
\text { Unskilled or semiskilled laborer }\end{array}$ & 15 & 19 \\
$\begin{array}{l}\text { Skilled laborer or lower white } \\
\text { collar worker }\end{array}$ & 54 & 58 \\
$\begin{array}{l}\text { Upper white collar worker } \\
\text { Professional or executive }\end{array}$ & 20 & 18 \\
\hline
\end{tabular}


TABLE6

\begin{tabular}{|c|c|c|c|c|}
\hline \multirow[b]{2}{*}{ Work classification } & \multirow[b]{2}{*}{$\begin{array}{l}\text { Total labor } \\
\text { force }(\%)\end{array}$} & \multirow[b]{2}{*}{$\begin{array}{l}\text { Minority } \\
\text { labor force }(\%)\end{array}$} & \multicolumn{2}{|c|}{ Epileptic patients } \\
\hline & & & $\begin{array}{c}V R A \\
(N=127) \\
(\%)\end{array}$ & $\begin{array}{c}\text { Clinical } \\
(N=69) \\
(\%)\end{array}$ \\
\hline \multicolumn{5}{|l|}{$\begin{array}{l}\text { White collar workers } \\
\text { professional and }\end{array}$} \\
\hline technical & 22 & 8 & 9 & 9 \\
\hline clerical & 18 & 16 & 12 & 13 \\
\hline sales & 8 & 3 & 10 & 6 \\
\hline Total & 48 & 27 & 31 & 28 \\
\hline \multicolumn{5}{|l|}{ Blue collar workers } \\
\hline operatives & 20 & 32 & 19 & 26 \\
\hline other blue collar & 19 & 16 & 7 & 10 \\
\hline Total & 39 & 48 & 26 & 36 \\
\hline Service workers & 12 & 22 & 22 & 13 \\
\hline Never employed ${ }^{a}$ & 1 & 2 & 21 & 23 \\
\hline
\end{tabular}

a Includes chronically unemployed who have no skill or trade and are unable to hold jobs for over a few days.

ity employment (Negro citizens). In 1969, the unemployment rate for the total labor force was $3.8 \%$ and, for the minority group $10.1 \%$; combining the two epilepsy groups, we find an unemployment rate of approximately $22 \%$ (Table 6). Our epileptic sample is not contaminated to a significant extent by the minority problem because $83 \%$ of our patients were white. The exact percentages differ somewhat between this table and the previous one because of different definitions used by the Michigan Employment Security Commission (Table 7). It is apparent that as far as professional and technical occupations are concerned, as well as those which are classified as services, the epileptic patient is more similar to the minority labor force than to the total labor force.

We can now argue that discrimination is the common bond which prevents the epileptic patient and the Negro citizen from rising to better employment opportunities. While in all probability this is true to an extent, it should not be accepted as the complete answer. Poor education is much more likely to be the most powerful factor which keeps both groups in the lower strata of society.

This brings us to the problem of prevention. Epilepsy starts commonly before or during the school years. What is lost in educational opportunities at that time is very difficult to recapture later on. If a child has a very active seizure disorder from let us say age 8 through 18 , learning will be impeded during this crucial decade and, even if seizures become a relatively minor problem in adult life, the educational lack can never be wholly compensated for. In our era of automation and mass technology, there are very few jobs left for the unskilled and uneducated. This problem will get 
TABLE 7

BREAKDOWN OF JOB CI.ASSIFICATIONS

\begin{tabular}{|c|c|}
\hline $\begin{array}{l}\text { Professional } \\
\text { draftsmen } \\
\text { artists (commercial) } \\
\text { engineers } \\
\text { personnel } \\
\text { physicians } \\
\text { instructors } \\
\text { technicians } \\
\text { managers } \\
\text { purchasing agents } \\
\text { self-employed } \\
\text { all other professional workers } \\
\text { Clerical } \\
\text { bookkeepers } \\
\text { cashiers } \\
\text { secretaries } \\
\text { clerks and storekeepers } \\
\text { typists } \\
\text { kindred workers } \\
\text { Sales } \\
\text { agents, brokers, underwriters } \\
\text { salesmen and clerks } \\
\text { all other sales workers }\end{array}$ & $\begin{array}{l}\text { Operatives } \\
\text { Labor (unskilled and other) } \\
\text { assemblers } \\
\text { checkers, examiners, inspectors } \\
\text { delivery and routemen } \\
\text { lathe operators } \\
\text { filers, grinders, polishers } \\
\text { machine operators } \\
\text { truck, boat and tractor drivers } \\
\text { kindred workers } \\
\text { Other blue collar } \\
\text { craftsmen } \\
\text { foremen } \\
\text { repairmen } \\
\text { kindred workers } \\
\text { Service workers } \\
\text { attendants } \\
\text { cooks } \\
\text { janitors and sextons } \\
\text { protective service workers } \\
\text { waiters } \\
\text { all other service workers } \\
\text { Unemployed } \\
\text { never employed and chronically } \\
\text { unemployed with no specific trade }\end{array}$ \\
\hline
\end{tabular}

worse instead of better. The cartoon statement: "Remember, you can be replaced by a button" is no longer merely a joke. In former years, the uneducated or uneducable could run elevators, shine shoes, do simple mechanical repairs, work on farms tending animals, etc. This is no longer possible, especially in the United States. The farms, in order to be productive, are mechanized, the elevators are automated, and worn-out goods for the most part are discarded instead of repaired. This is the pattern of the future and it will not remain limited to the United States, but will also affect the highly technologically advanced countries of Europe.

When it comes to the education of children with epilepsy, it is argued that they should not be separated into special classes, but should attend regular school lest they feel as outcasts. If a child has seizures in class, this should be turned into a learning experience for the rest of the pupils to indicate that epilepsy is harmless and nothing to be afraid of. While this can undoubtedly be accomplished in some instances, it will not work in others. The fundamental underlying philosophy on which this course of action is based assumes that children are kind to each other and are endowed with at least as much, if not more, pity than the average adult. I believe this not to be the case. The adult can learn compassion because of some of his own unhappy life experiences, but the child who is in good mental and physical health will either ignore 
the afflicted or, more commonly, ridicule him. "Thou shalt not ridicule thy fellow pupil" may be a commandment a teacher can expound ex cathedra, but it is not likely to be heeded by all the members of the class and it takes only one vicious bully to leave permanent scars on a patient.

Special education for epileptic children has been abolished for all practical purposes, because " $90 \%$ can be taken care of through regular educational channels" (Tenny 1953). These children do indeed go to regular classes, but the question is: Are they learning something or are they merely spending time in school? Of 118 children seen between January, 1965 to January, 1971 at the Epilepsy Center of Michigan, 87\% were attending or had attended regular school; $32 \%$ were or had been in special classes. The percentages do not come up to 100 because there is movement between the two groups. We can again be satisfied and state that the educational problems of the vast majority of epileptic children are therefore adequately taken care of. But let us look at school performance (Table 8). Fifty-six percent were doing unsatisfactory work or had failed grades. There were no honor students in the sample. This is not due to discrimination, but in all probability reflects the intelligence level. The earlier epilepsy starts, the more likely it is to be associated with intellectual difficulties (Table 9). To ignore this fact and state that the majority of epileptic children are just as normal as their classmates, except for having an occasional seizure, may be a serious mistake. The child himself knows on occasion that he is not as bright as his sibling. He will tend to play with younger children rather than those of his own age and he will experience failure in school. He is likely to learn to accept and expect failure and when he has completed his tour of duty in school by age 16 , he is totally unprepared to enter a highly competitive society requiring skills which he has not had the opportunity to acquire. What should be done? I believe that the time has come where we have to leave stereotype and shun global answers that apply to "the epileptic". All

TABLE 8

AVERAGE SCHOOL GRADES OF EPILEPTIC CHILDREN

$(N=102)$

\begin{tabular}{lr}
\hline & $\%$ \\
\hline Unsatisfactory and grade failure & 35 \\
Unsatisfactory but no grade failure & 21 \\
Average & 27 \\
Somewhat above average & 17 \\
Superior or honor student & 0 \\
\hline
\end{tabular}

TABLE 9

RELATIONSHIP BETWEEN WECHSLER INTELLIGENCE SCORE AND AGE AT ONSET OF EPILEPSY

\begin{tabular}{lccc}
\hline $\begin{array}{c}0-3 \text { years } \\
(N=27)\end{array}$ & $\begin{array}{c}4-12 \text { years } \\
(N=31)\end{array}$ & $\begin{array}{c}13-27 \text { years } \\
(N=30)\end{array}$ \\
\hline Full Scale IQ & 84.8 & 90.4 & 101.3 \\
\hline
\end{tabular}


epileptic patients have only one feature in common, namely, intermittent seizures and, as we know, even these vary markedly in frequency and severity among different patients. But apart from having seizures, each patient is an individual with specific assets and liabilities. It is not sufficient to treat seizures and ignore the rest of the person.

At the present time, when a child develops his first seizure, he is usually given a thorough neurological evaluation, frequently in a hospital-which may include even pneumoencephalography, brain scan, arteriography -in order to detect an underlying illness. This workup is negative in the vast majority of instances, and the patient is then placed under observation without medication or put on phenobarbital diphenylhydantoin (Dilantin ${ }^{\circledast}$ ) or both until the next seizure develops. His anticonvulsant regime may or may not be rearranged at that time. I do not want to imply that a careful medical workup should not be undertaken, but I do want to say that it is insufficient to concentrate only on trying to find "the cause" of his epilepsy without assessing the patient's intellectual functions and personality. Rehabilitation ought to start at the time of first evaluation. If the child is found to be intact in all other respects apart from the seizure(s) and he is of school age, he should certainly continue in regular class, although it would be wise to warn him that he might "pass out" again. If IQ testing reveals that the patient has lowered intelligence that will not allow him to compete effectively with his peers, he should receive special education which is tailored to help him make passing grades in the areas where he is weak but, even more importantly, to concentrate on teaching him a skill in an area of his interest and unimpaired functions.

This is what should be done, but it is not likely to come to pass for the majority of our patients because the type of special education that we have mentioned is expensive and school boards in the United States can hardly make ends meet for their regular educational program. Epilepsy is not a popular cause and probably never will be. Only a relatively small segment of the total population is affected and it is therefore unrealistic to hope for public funds to come pouring in to help with the educational needs. The problem may have to be solved through organizations of parents creating private sources of funds and educational opportunities.

It has been mentioned above that our society is becoming increasingly complex and will require new skills for persons to become reasonably successful. Neither the physician nor the social worker can hope to keep up with areas of employment which are either closing down or opening up. The skilled rehabilitation counselor is likely to become an increasingly important person in the management of some epileptic patients. There is evidence in the literature that rehabilitation counselors tend to shun patients with epilepsy at the present time because they are "poor risks" (Goldin 1966). The rehabilitation worker is under pressure from his superiors to produce closure of cases by placing his clients either in a job or training situation. He tends to get more than his fair share of the "hard core" (what we call poor employment prognosis) group, and this in turn reinforces his negative attitudes. Furthermore, the average rehabilitation counselor is not sufficiently familiar with the medical aspects of seizure patients and the possible side reactions of anticonvulsants. He would much 
rather work with hemiplegic or blind patients whose performance is not likely to vary on a day-to-day or week-to-week basis, as may be the case in certain seizure patients. To help our more difficult epileptic patients best would require the training of vocational rehabilitation specialists who are interested in this disorder, and are willing to learn the essentials of what is known about epilepsy and what type of behavior they can expect from their clients. Under optimal circumstances, rehabilitation counselors would begin to work with certain patients while they are still in school so that habilitation rather than rehabilitation can be effected. The data which we have presented here may be of use to rehabilitation counselors. By concentrating initially on those patients whose rehabilitation prognosis is reasonably good, they will experience greater success in placing patients and they will lose their own negative attitudes towards epilepsy.

We have to remove the stigma that is still attached to the diagnosis, but this can only be accomplished through positive experiences and not through exhortation, changing the name of the illness or covering up our failures. We must admit that problems exist, but it is equally important to identify those patients whose problems have been solved and who are working in positions which are held in esteem. This would require an act of considerable personal courage, but remitted patients can do infinitely more to remove the stigma than any admonition from professional sources. It is the living example which counts. We publish in our lay literature that great men like Caesar, Dostoevski, etc., had epilepsy to which the names of several more luminaries are usually thrown in for good measure, like Alexander the Great, Byron, Napoleon, etc., for whose seizure disorders there is actually hardly any evidence. But be this as it may, the child or adult with epilepsy can hardly be asked to identify with Caesar or the others of whose existence he usually has only very vague notions. What he needs is the physician, the lawyer, the nurse, the TV star, the banker and the business man in his community to come out and say, yes, I have had or still have epilepsy. Their example would do infinitely more good than any reference to past heroes. As Dr. Zieliński has already mentioned, the public sees, unfortunately, mainly those epileptic patients who are in difficulty of some sort or another and, propaganda notwithstanding, people tend to believe what they see rather than hear. The epileptic patient whose illness is of such a nature that it can be hidden would be the best salesman for making the disease as acceptable as diabetes or coronary artery sclerosis, for instance. We have recently seen an isolated act of personal courage in this respect. A reasonably well-known TV actor and writer admitted in public to having had a rather severe form of epilepsy during adolescence and early adulthood. He took the chance of jeopardizing his career by this unsolicited admission. If there were more like him who can discuss their illness with courage and dignity and are in prominent positions, we would make genuine, rapid progress in overcoming fear and prejudice and thus help also those of our patients whose illness is still of major proportions.

SUMMARY

The results of a study to elicit factors which are associated with an epileptic patient's 
gaining and keeping employment are presented. Eighty-seven employed patients were compared with 90 unemployed patients on a wide variety of variables. It was found that the employed patients had higher intelligence, less impairment on neuropsychological tests, less neurological and electroencephalographic abnormalities, and their work history was considerably better than that of the unemployed group. A step-wise discriminant function analysis revealed that the most powerful predictors for employment success were: high motivation for work, good verbal IQ, a self confidence item, and the patient's present level of socialization.

A review of the type of employment held by our patients, when compared against the total labor force and the minority labor force (Negro citizens) of the Detroit Metropolitan area, showed that the epileptic patients tend to be similar to the minority labor force, clustering in the lower socio-economic brackets. It was felt that discrimination against both groups is probably only one common denominator. Another, possibly a more important one, is inadequate schooling which results in failure to acquire the skills needed for living successfully in a highly technological, complex, competitive society. It is pointed out that although the majority of epileptic children attend regular schools, their grades tend to be below average and that they are not being prepared for entering the competitive job market. Suggestions how to improve this situation through rehabilitation efforts during the school years and how to more effectively remove the stigma from the illness are also presented.

\section{REFERENCES}

Dennerll, R., Problems of rehabilitation and employability in epilepsy. In: E. Niedermeyer (Ed.), Modern Problems of Pharmacopsychiatry Epilepsy, Karger, Basel, 1970, pp. 326-337.

Dennerll, R., Rodin, E., Gonzalez, S., Schwartz, M. and Lin, Y., Neurological and psychological factors related to employability of persons with epilepsy, Epilepsia (Amst.), 1966, 7: 318-329.

DenNerll, R., Schwartz, M. and Rodin, E., Neurological, psychological, and social factors related to employability of persons with epilepsy, Final Report, VRA Project No. RD-1403-P, Epilepsy Center of Michigan, 1968, pp. 1-101 (available from the Epilepsy Center of Michigan).

DE TORRES, T., Employment problems of epileptics. Research and Demonstration Grant No. 382, Office of Vocational Rehabilitation, Department of Health, Education, and Welfare, Washington, D.C., 1963.

Goldin, G., Some rehabilitation counselor attitudes toward their professional role. Rehab. Lit., 1966, 27: 360-369.

JUUL-JENSEN, P., Vocational training of epileptics, Epilepsia (Amst.), 1961, 2: 291-296.

KETZ, E., Sozialproblematik und psychopathologie bei Epilepsie, Schweiz. Rdsch. Med., 1970, 59: 327-333.

PORTER, R., Epilepsy and employment, Irish J. med. Sci., 1968, 7: 83-90.

Rodin, E., Medical and social prognosis in epilepsy, Epilepsia (Amst.), 1972, 13: 121-131.

TenNY, J., The minority status of the handicapped, Except. Child., 1953, 19: 260-264.

WALKER, E., Prognosis in posttraumatic epilepsy: A ten-year follow-up of craniocerebral injuries of World War II, J. Amer. med. Ass., 1957, 164: 1636-1641. 